\title{
GIROLAMO VITTORI Y CÉSAR OUDIN: UN GASO DE PLAGIO MUTUO
}

No existe, que yo sepa, ningún estudio de importancia sobre los primeros diccionarios españoles, o sea, los publicados entre 1492 (Vocabulario español-latino de Nebrija) y 1726 (Diccionario de Autoridades, de la Real Academia Española). Todos esos diccionarios son ya obras muy raras, pues sólo se han reimpreso los dos más significativos: el Vocabulario de Nebrija (en edición facsimilar) y el Tesoro de la lengua castellana de Covarrubias (1611). Sería de gran interés hacer investigaciones detalladas acerca de las fuentes de todos esos primitivos vocabularios, de su cronología y dependencia relativa; habría que precisar hasta qué punto son dignos de confianza, así como la capacidad y honradez lingüística de sus autores; convendría conocer qué relación guarda la $\mathbf{1}^{\mathrm{a}}$ ed. de cada una de esas obras con las ediciones sucesivas, y determinar el verdadero alcance de la fórmula "corregido, revisado y aumentado en esta última edición". Los únicos ensayos de valoración crítica hechos hasta el momento se deben a Samuel Gili Gaya y a quienes colaboraron con él en la preparación del monumental Tesoro lexicográfico (Madrid, 1947. 1957; letras A-G), en el cual, sin embargo, se han deslizado algunos errores que podían haberse evitado si se hubiera contado con una serie de estudios monográficos previos. Una magnífica muestra de los problemas relativos a ese capítulo de la primitiva lexicografía española, nos ofrece el Tesoro de las tres lenguas española, francesa y italiana (Ginebra, 1609) de Girolamo Vittori (o Hierosme Victor). Varias noticias confusas, casi misteriosas, giran en torno a este diccionario. Germán Colón, en sus comentarios "A propos du Tesoro lexicográfico de M. Gili Gaya” ( $\left.Z R P h, 72,195^{6}, 379^{-3} 86\right)$, afirma en relación con la fecha del Tesoro de Vittori: "De même la première édition du dictionnaire trilingue de Vittori date de 1606 et non de 1609 ", y en nota añade: "L'édition de 1606 contient seulement une partie espagnole (avec traduction en français et en italien) et une partie française (avec traduction en italien et en espagnol). Il y manque la partie italienne que nous retrouverons en 1609 . Nous avons pu observer que les mots italiens qui traduisent l'espagnol ou le français ont été quelque peu remaniés dans l'édition de 1637 " (p. 382). 
Antes de señalar los errores encerrados en estos pasajes, será conveniente recordar lo que sobre el mismo Vittori escribió Charles Brunot en su Histoire de la langue française" "Il se pose pour Victor un petit problème d'éditions. On donnait ordinairement comme première édition: 1606 . . Cette première édition n'est pas en réalité la $1^{\text {re }}$ édition. Elle est copiée de C. Oudin, qui le déclare formellement dans son édition de $1616 \ldots$ alors la première édition serait celle de $1609 .$. La date 1606 serait donc une erreur ou un mensonge". Y, refiriéndose al plagio cometido por Vittori, precisa: "Son Dictionnaire est celui de César Oudin démarqué lettre pour lettre. Il y a simplement joint une traduction italienne" (p. 82).

Por su parte, Gili Gaya, en la bibliografía que incluye al frente de su Tesoro, si bien no hace mención a este problema de la fecha ${ }^{2}$, repara también en la falta de originalidad de Vittori: "Como suele ocurrir en la mayor parte de los diccionarios plurilingües, tiene poca originalidad; está basado en Las Casas para la parte española-italiana, y en Oudin para la hispano-francesa" (p. xxıv).

Ninguná de estas tres opiniones es enteramente cierta; en todas ellas hay algún error, expreso o implícito.

Yerra Colón al afirmar que la primera edición de Vittori es de 1606 y no de 1609 como acertadamente sostiene Brunot. Yerra también cuando asegura que la tercera parte ("la partie italienne") aparece en 1609 , ya que la edición de ese año contiene sólo dos partes, una de español-francés-italiano y otra de francés-español-italiano. Se equivoca además, aunque sólo cuantitativamente, al decir que las traducciones italianas "ont été quelque peu remaniés" en la edición de 1637 , puesto que, en realidad, los cambios van desde la simple corrección de errores tipográficos a la sustitución de las definiciones italianas por otras completamente nuevas y muy superiores (cf. infra, p. 16$)$.

Las deducciones de Brunot referentes a las ediciones de 1609 y 1606 son acertadas, pero no lo es la tajante acusación de plagio, según procuraré demostrar basándome en el gran número de discrepancias que se aprecian entre los diccionarios de Oudin y de Vittori.

Tampoco la opinión de Gili Gaya es aceptable, ni en lo que afirma ni en lo que silencia: no creo que pueda afirmarse que la parte hispano-italiana del vocabulario de Vittori esté hecha sobre Las Casas; y, al referirme a lo que Gili calla, pienso en el descarado plagio que Oudin hizo, en la $2^{\text {a }}$ edición de su obra, del Tesoro de Vittori de 1609 .

Me propongo aquí, en primer lugar, caracterizar y evaluar el Tesoro de Vittori en sí mismo, y hacer después varios análisis particulares para resolver ante todo el problema relativo a la fecha de

1 T. 3, $1^{\text {re }}$ partie, Paris, 1 gog, pp. $82-83$, nota 3.

2 Acaso Gili Gaya no tuviera noticia de esa edición supuesta de 1606 . 
la primera edición del Tesoro, y para establecer luego varias relaciones: a) entre el Tesoro de Oudin de 1607 (primera edición) y el de Vittori de $1609 ; b)$ entre la edición de Vittori de 1609 y la de Oudin de 1616 (segunda edición); y $c$ ) entre las ediciones sucesivas de la obra de Vittori, es decir, las de 1609 , 1606 (1616?), 1637 y 1644 . Por último, haré algunas observaciones sobre la posible fuente -o fuentes- que usó Vittori aparte del Tesoro de Oudin.

Quien por primera vez acusó a Vittori de plagiario fue el propio Oudin, en el "Advertissement aux lecteurs" de la segunda edición de su diccionario, al aludir despectivamente a cierto personaje - sin mencionar su nombre- que había plagiado descaradamente la primera edición de su obra: "I'adiousteray à l'advertissement cy dessus, que ceux qui ont fait imprimer ce Tesoro à Genève, avec l'addition de la langue italienne, et de quelques dictions Espagnoles fournies par d'autres, n'ont pas oublié de s'attribuer l'honneur de l'avoir compilé..." Y para confirmar la acusación, Oudin añade esta irónica observación: "En outre, i'eusse desiré que celuy qui y a adiousté l'Italien, eust mieux entendu les deux autres langues, car i'ay trouvé en l'explication seule de ce qui n'est pas mesme une lettre entière, il a laissé eschaper de sa plume cinq ou six absurditez; et afin de prouver mon dire, vous verrez qu'en interpretant le cedilla, que i'ay expliqué ainsi: la virgule qui se met soubs le $c$ pour le faire prononcer comme $s$ devant $a$, o et $u$, ce messire fricasse l'expose ainsi par ces mots Italiens, lo accento acuto che si mette sopra la lettera dalla voce per farla sonare". Oudin explica entonces seriamente el error de semejante explicación, y termina diciendo: "Advisez donc s'il y peut avoir d'autres pas de clerc au reste du livre". Estas alusiones de Oudin son de sumo interés, ya que nos permiten identificar sin lugar a dudas al plagiario ginebrino: en el Tesoro de Vittori de 1609, y también en las ediciones siguientes, s. v. cerilla (dentro de la cual se incluye la variante cedilla) aparecen exactamente las palabras que cita Oudin.

De paso, podemos observar que Oudin no identifica a su imitador, hecho que podría ser muy significativo; y también que el pormenor con que se refiere a la errónea explicación de Vittori, acaso sea prueba de que había examinado con mucho detenimiento la obra de éste; después volveremos sobne ello.

Observando de cerca el Tesoro de Vittori, se aprecia inmediatamente su deuda para con Oudin: las páginas preliminares son copia directa del "Advertissement necessaire aux lecteurs touchant l'ortographe de la langue espagnolle, et du moyen de faire son profit du present recueil" que encabeza el Tesoro de Oudin (ed. 1607). Este Advertisse. ment va seguido de un breve prefacio en italiano, firmado por Girolamo Vittori, en el cual declara, entre otras cosas, que ha hecho un gran esfuerzo para traducir al italiano un diccionario hispano-fran- 
cés: ". . . nella traduttione di questo dittionario Spagnuolo, et Francese, in lingua Italiana. . . io non ho usate altre voci, che quelle, che io ho imparate da scrittori famosi, che hanno scritto in detta lingua nobile Toscana, tanto in prosa, che in versi, et cio cum mio lungo, et continuo studio, come apparera dalla lettura di essa traduttione, per chi vodravi spendere il tempo". Vittori se muestra deliberadamente impreciso al aludir al autor del diccionario español-francés que había traducido. No afirma que él sea el autor, pero tampoco asienta que no lo es. Por otra parte, habría mucho que decir sobre la calidad de esa traducción.

Antes de entrar en detalles acerca del grado de plagio cometido por Vittori, creo conveniente determinar la fecha exacta de la primera edición de su Tesoro. Indudablemente no puede ser la de 1606, por varias razones: 1) El diccionario de Oudin, de que se sirvió Vittori, se publicó por primera vez en 1607 . Si esta fecha es correcta - y no hay razón alguna para dudarlo- la del Tesoro de Vittori tiene que ser un error. 2) En la portada del volumen de 1606 se indica: "derniere edition reueuë et augmentee en plusieurs endroits”, observación que no aparece en la edición de 1609. 3) La portada de la Parte II (francés-italiano-español) está fechada en Mocxvi en Cologni; la fecha de mocvi que aparece en la portada de la parte I será, pues, un simple error de imprenta. 4) La edición de 1606 contiene muchos errores tipográficos que no aparecen en la de 1609 , pero sí en las de 1637 y 1644 ; esto probaría, al menos, que la edición de 1606 sirvió de modelo a las dos últimas.

Un análisis detallado de estos cuatro puntos nos permitirá solucionar definitivamente el problema y a la vez nos servirá como introducción al estudio de la obra. He cotejado diez páginas de la edición de 1609 (Parte I) con las correspondientes de la edición de 1606 , y he hallado - aparte de errores comunes- otros que aparecen en 1606 y no en 1609 , y sólo tres exclusivos de esta última edición. Esto, si no es prueba definitiva, por lo menos hace sospechar que la supuesta edición de 1606 tiene que ser posterior a la de 1609 .

Prescindiendo de esos errores comunes a las dos ediciones, ofrezco a continuación una lista de los errores que se advierten en la edición de 1606 pero no en la de 1609 . (El asterisco significa que el error se repite en la ed. de ${ }_{1637)}$ :

VITTORI 1606

* Abeiaria

Abeion,. . . ape bastarde, che non

fenno mele

* Abiertamente,... appertamente

* Abitudo

* Abonase eli tiempo
VITTORI 1609

Abeieria

fanno

apertamente

Abitud

el 
Abondosamente... epulemment

* Abotonar los arboles, Brotar,... permogliare

Absorto en una cosa,... attacato

* De $c$ a

* Acachar,... abbatere

* Acadarrado, o Acatanado

* Acañalado, faict de canes Acanonear,... bombardar con bonbarde

* Acarrear,... carregiare ...opulemment

germogliare

attaccato. (En la ed. de 1637 se da otra explicación y no aparece esta palabra).

De aça (también error por de acá)

abbattere

Acatarrado

cannes

bõbarde (En la ed. de 1637 se cambia la definición, pero cf. Acanoneado en donde aparece bom-)

carreggiare

Finalmente, sólo he hallado tres erratas de la edición de 1609 que no aparecen en la de $\mathbf{1 6 0 6 \text { : }}$

\section{VITTORI 1609}

Abono, Abonança, caution, pleige seureté

Abosolucion,

Acomodado,... addattato
VTrTORI 1606

pleige, seureté

Absolucion

adattato

Volvamos ahora a la cuestión del plagio. Recordemos la opinión de Brunot en el sentido de que el diccionario de Vittori era copia del de Oudin con la simple adición de definiciones italianas. Si cotejamos detenidamente ambos vocabularios, llegaremos a la conclusión de que es necesario rectificar en gran parte esta opinión. Es cierto que Vittori copió casi toda la obra de Oudin sin hacer modificaciones importantes, pero también hay que señalar que el libro de Vittori contiene aproximadamente 3,00o artículos nuevos. Además se aprecian innumerables diferencias de detalle con el texto de Oudin.

Antes de mostrar estas diferencias, debemos reparar en una extraña circunstancia: que Vittori, en ningún lugar de las cuatro ediciones de su obra que he consultado, declara haber aumentado o corregido el diccionario que traducía. Este silencio no puede deberse a modestia. Ya hemos visto que en el prefacio de su primera edición, Vittori se muestra deliberadamente impreciso al hablar de la paternidad del diccionario. Como es lógico, si hubiese declarado que introducía adiciones o correcciones, se habría visto obligado a indicar a qué obra hacía tales enmiendas. Posiblemente, mejor que enorgullecerse de ser el autor indudable de una parte de la obra, prefirió dar vagamente a entender que toda ella le pertenecía.

El siguiente análisis se basa en un cotejo detallado de las diez 
primeras páginas del vocabulario de Vittori (ed. 16og) con las correspondientes del de Oudin (ed. 1607). Rara vez se aparta Vittori de su modelo; en algunos pocos casos omite artículos que sí aparecen en el francés. Las únicas omisiones que hallo en esas diez páginas (debidas posiblemente a inadvertencia) son: abasto, voyez abastança, acaso, aclaramiento acobardar, acobardado, acreedora.

Por el lado positivo, y empezando por lo menos importante, observamos que Vittori hace algunos cambios de distinto género en el texto de Oudin. Por ejemplo, en varios casos elimina el renvoi usado por Oudin, y ofrece la explicación sin más rodeos, lo cual resulta más cómodo para el lector:

\section{OUdin 1607}

Abla, voyez Exe

Exe, l'essieu d'une rouë

Abochornado, voyez Abuchornado.

Abuchornado, bruslé et haslé du vent de Midi, flestri, seché.

Abolengo, voyez Abolorio.

Abolorio, genealogie, race.

Acrecentar, voyez Acrescentar.

Acrescentar, o Acrecentar, accroistre, augmenter, amplifier. Abastecer, voyez Bastecer.

Bastecer, fournir, garnir, munir, pourveoir de vivres et autres choses necessaires.

\section{VITTORI 1609}

Abla, Exe, aissieu d'une rouë Exe [como en Oudin] Abochornado, Abuchornado, fletry, bruslé et haslé du vent du Midi.

Abuchornado [como en Oudin]

Abolengo, Abolorio, genealogie, race des ancestres.

Abolorio [como en Oudin]

Acrecentar, Acrescentar, accroistre.

[Como en Oudin]

Abastecer, Bastecer, munir, garnir, et fournir de choses necessaires.

Bastecer [como en Oudin].

Estos pasajes muestran que Vittori es unas veces consecuente y otras inconsecuente en su modo de hacer las anotaciones: consecuente, en cuanto que copia sin cambio alguno la definición que ofrece Oudin en el renvoi, como en exe, abuchornado, abolorio, acrescentar. Inconsecuente, por cuanto que a veces altera imprevisiblemente las explicaciones originales de Oudin (abla, abochornado, abolengo, acrecentar), ofreciendo por lo general un resumen de la definición dada en el renvoi.

En una ocasión, se toma la molestia de combinar en una sola las definiciones de dos artículos distintos de Oudin, aunque conserva separados ambos artículos, como en el diccionario de Oudin: 
OUdiN 1607

Abonar, pleiger, cautionner, pleuvir.

Abonar, o Abonançar el tiempo, appaiser, rendre tranquille.
VITTORI 1609

Abonar, calmer, rendre calme et tranquille, pleiger, cautionner, pleuvir.

[Como en Oudin].

En otras ocasiones, Vittori altera las definiciones de Oudin, ya sea omitiendo parte de ellas, ya sustituyendo o modificando algún elemento. En los ejemplos siguientes, cito sólo lo imprescindible del artículo, y pongo entre corchetes lo que Vittori omite. Únicamente en los casos en que la modificación introducida es más complicada, reproduzco el texto de Vittori:

OUdN 1607

VITTORI 1609

Abastança, [a] suffisance, [en]

abondance.

Abiltar, [casi] Abatir,

Acordar [a otro],

[Acosar o] Acossar,

Abrego o Abrigo [Viento lluvioso],

Abubilla, [Ave],

Abenuz, [Arbol de madera negra, Abenuz, o Ebano, ebene.

un arbre qui a le bois noir],

ebene.

Abusion, abus, [abusion].

Acordar, Despertar a otro, esveiller un autre.

Abispon o Tavarro, le freslon [ou foulon].

Abarca, une espece de chausseure de paysan, [comme seroit une guestre, ou triquebouse, gamache: c'est aussi une sorte de brodequin, sabot, galoche].

Abusion, abus, superstition.

Acordar, Despertar a otro, esveiller autruy.

Abispon o Tavarro, le freslon, grosse mouche.

Abarca, une espece de chausseure de paysan, qui enveloppe les pieds avec drap, puis les couvre par dessus de cuyr crud, lacé avec cordes.

Con excepción de todas estas modificaciones, el texto del Tesoro de Vittori es exactamente igual al de Oudin; sin embargo, todavía hay que señalar dos diferencias muy importantes; constituyen la primera los artículos añadidos por Vittori, y forman la segunda las adiciones que hace a las definiciones dadas en la edición de 1607 de Oudin.

En las diez primeras páginas de Vittori, encuentro 62 artículos que no aparecen en Oudin. En el conjunto de la obra cabe esperar, proporcionalmente, un aumento de cerca de tres mil artículos. Confieso que me sorprendieron estas adiciones, ya que Vittori nada dice 
de ellas ni se vanagloria de tal labor original; pero ciertamente me sorprendió mucho más descubrir que Oudin había aprovechado casi las tres cuartas partes de estas adiciones, en la segunda edición de su Tesoro.

Es preciso indicar que el gramático francés jamás reconoció deuda alguna para con Vittori, sino que - como vimos- se limitó a acusarle públicamente de plagiario. Para tratar de explicarme el hecho de que casi dos mil de los artículos añadidos en la edición de Oudin de 1616 coincidan con los de Vittori, se me ocurrió pensar que acaso el francés, inmediatamente después de la aparición de su Tesoro, empezara a recoger nuevos materiales con la intención de incluirlos en la segunda edición de su obra; entraría entonces en contacto con Vittori, quien quizá hubiera expresado su deseo de traducir el libro al italiano; Oudin pudo ofrecerle su obra, junto con todos los nuevos materiales ya acumulados, para que los incluyera en la edición italiana; Vittori debió de cambiar de propósito, y decidió apropiarse de los materiales recogidos por el gramático francés; sin embargo, pronto me vi obligado a rechazar esta explicación por razones que en seguida mostraré.

Estoy absolutamente seguro de que Oudin plagió a Vittori tan decididamente como éste le había plagiado antes a él, y sin remordimiento alguno, justificando su acción como natural represalia. Además, conviene recordar que este tipo de despojos era bastante frecuente en aquella época.

De las 62 primeras adiciones hechas por Vittori, todas, salvo 13 , se hallan en Oudin, 1616; sólo faltan las siguientes:

a) abalançarse a los peligros, ablandar lo duro, acaba ya, aca y alla, de aca, acocear hazia tras; b) quien la abezó tanta filosofia, abusiones de viejas, acomplimento, acrescentador; c) abiltado, abatido; abotonado, abrochado; aclarado; d) quien mucho abarca poco aprieta. Quizá Oudin excluyó estos artículos por las siguientes razones: los del grupo $a$ pudieron parecerle refinamientos innecesarios, pues sus significados pueden derivarse fácilmente de la significación propia del verbo; los del grupo $b$ se le antojarían acaso arcaísmos o expresiones poco usuales; los del grupo $c$-a los que nada podía reprochar Oudin, según se desprende de las voces recopiladas en su Tesoro- pudieron omitirse por descuido; y en lo que respecta a $d$, hay que advertir que muy rara vez admite Oudin refranes en su diccionario.

De las 62 adiciones originales de Vittori, 49 se hallan, pues, en la segunda edición de Oudin: 1) algunas se repiten letra por letra; 2) otras fueron ampliadas; y 3 ) otras se modificaron en alguna manera. Forman el primer grupo 20 artículos, entre los cuales se hallan abandonar, abantar, abaxador, abito, abundosidad, etc. He aquí algunos ejemplos (cito por Oudin, 1616): 
Abandonar, proclamer, faire un ban et cri public.

Abantar, voguer avant, advançer.

Abaxador, tondeur de draps.

De los 12 artículos que forman el segundo grupo, transcribo los más representativos del tipo de adiciones que le gustaba hacer a Oudin ${ }^{3}$ :

1. Absorto en una cosa, qui est du tout attaché a une chose, et comme [ravi et] espris.

2. Abto, propre, idoine, apte, [convenable].

3. [Voz ou] Boz abultada, grosse voix [et bien remplie].

4. Aclarador, esclaircisseur, [qui declare et desbrouille quelque chose].

5. Aba el lobo, gare le loup, cri que l'on fait au loup [quand il vient pour prendre quelque proye].

6. Acabar con alguno, chevir de quelqu'un, [obtenir et] impetrer de quelqu'un.

7. Acrevillar, percer [et troüer] en façon de crible, [c'est aussi cribler].

La definición 1 es ejemplo de adición feliz: la voz ravi no sólo añade equilibrio a la glosa, sino que además expresa una emoción que sirve como de introductora lógica de espris.

Estos ejemplos sólo prueban que Oudin no se conforma con explicaciones que son simplemente aceptables, sino que se esfuerza por darles mayor claridad y precisión. El artículo 5 es un buen ejemplo: la explicación de Vittori sería totalmente inteligible para los lectores educados en el campo o para los burgueses conocedores de las costumbres de los lobos; sin embargo, un buen lexicógrafo no tiene por qué suponer conocimientos particulares en los lectores de su obra; por ello es muy oportuna la puntualización de Oudin, quand il vient... proye.

En el tercer grupo de préstamos, constituido por 8 artículos, Oudin modifica verdaderamente las definiciones de Vittori; y en algunas hace también adiciones (subrayo la parte del texto modificada):

1. Vitt.: Acodar vides o plantas, couder, provigner.-Oud.: . . couder, eschalasser vignes ou arbres ${ }^{4}$.

2. Vitt.: Deabaxo arriba, cen dessus dessoubs.-Oud.: Lo de abaxo arriba, sens dessus dessoubs, le haut en bas.

${ }^{3}$ Cito también por Oudin 1616 , y pongo entre corchetes lo añadido por él; salvo indicación en contrario, el resto de las definiciones no ofrece cambios.

${ }^{4}$ Oudin parece haberse equivocado aquí. Según Covarrubias, acodar las vides significa plantarlas haziendo una torcedura de manera de codo; de aquí, acodar. $\mathrm{Y}$ esto debe hacerse mientras el tallo está todavía unido a la cepa, con el fin de que pueda convertirse en nueva planta. La definición de Vittori implica esta significación, pero no el eschalasser de Oudin, que significa sólo 'sostener, estacar o apuntalar', sin aludir a la idea de propagación. 
3. Vitt.: Acoralado, garny ou orné de courail.-Oud.: ... garny et orné de courail.

4. Vitt.: Abrir un cuello, gaudronner une fraise--Oud.: gaudronner un collet $\grave{a}$ fraise.

5. Vitt.: Absortar y detener el ingenio, occuper $d u$ tout et detenir entierement l'esprit. - Oud.: . . .occuper et detenir entierement son esprit, s'estonner, s'esbahir.

6. Vitt.: Acanelado, assaisonné et accommodé avec canele. - Oud.: ... assaisonné avec de la canelle.

7. Vitt.: Acapado, bouché de manteau. - Oud.: ... bouché d'un manteau ou cape.

La modificación hecha en el caso 2, que afecta al epígrafe del artículo, aparece muy raras veces. Los ejemplos 3 y 4 prueban el interés de Oudin por el detalle y la exactitud. El 5 es sobre todo una muestra de propiedad lingüística; lo mismo puede decirse de los dos últimos. En muchos casos, para ser más exacto, recurre Oudin a algún artículo indefinido que falta en la definición de Vittori; también, aunque con menor frecuencia, añade un artículo definido o partitivo:

Vitt.: Fresas, freses, fruict. - Oud.: ...des fraises, fruits.

Vitt.: Herron, [s]eau ferré a puyser l'eau. - Oud.: . . . un seau ferré a puyser de l'eau.

Vitt.: Fonsadera, denier pour reparation des murs d'une ville.

- Oud.: ... deniers pour la reparation des murs d'une ville.

En las páginas anteriores hemos visto cómo Vittori ampliaba el texto de Oudin con numerosas adiciones. Además, en miles de casos - a juzgar por las 10 primeras páginas- haría más extensas las definiciones francesas (encuentro casi $5^{\circ}$ ampliaciones en esas páginas iniciales). Para ello, sospecho que Vittori cotejó cuidadosamente el Tesoro de Oudin con otro o con otros diccionarios, de los que tomaría algunos significados no recogidos por el gramático francés. Sin conocer esas fuentes, sólo hipotéticamente puede juzgarse el criterio seguido al hacer tales adiciones. En la mayoría de los casos parece haber sido acertado; por lo general añade un sinónimo o una nueva acepción, mediante la inclusión de una sola palabra o, en algún caso, de una frase.

Comparando esas definiciones ampliadas con el texto de Oudin 1616, advertimos los hechos siguientes: 1) Varias de esas definiciones se repiten sin cambio alguno en el diccionario de Oudin; 2) otras tantas faltan por completo; y 3) unas pocas aparecen algo modificadas. Como no nos es posible determinar con certeza qué criterio seguía Oudin para aceptar o rechazar las amplificaciones de Vittori, mis explicaciones no pasan de ser meras hipótesis o sugestiones.

De los tres grupos mencionados, es el tercero el único que se 
presta a un análisis objetivo, ya que disponemos de tres textos a través de los cuales se pueden analizar dichas variantes. Cito a continuación todos los casos de ampliación, excepto uno, que aparecen en las 10 primeras páginas de Vittori. A simple vista puede apreciarse, en primer lugar, cómo amplía las definiciones de Oudin ${ }_{160} 7$ (lo añadido por él va entre corchetes), y, en segundo, cómo esas adiciones se repiten en la $2^{\text {a }}$ edición del diccionario de Oudin ${ }^{5}$ :

1. Oud. 1607: Abaratar, vendre a bon marché. - Vitt. 1609: ..., [avilir de prix]. - Oud. 1616: ..., [ravaler].

2. Oud. 1607: Abollado, escaché, meurtri, enfoncé, froissé. - Vitt. 16og: ..., [bosselé, vessié, raturé]. - Oud. 1616: ..., [bosselé, vessié, bossué].

3. Oud. 16o7: Abarcar pour Abraçar, embrasser, accoller, haper. Vitt. 1609: ..., [agrapper, pousser, lancer]. - Oud. 1616: ..., [agrapper].

4. Oud. 1607: Acaudillar, commander et conduire gens de guerre, duire et accoustumer a une chose. -Vitt. 16og: commander, conduire et [faire troupe de] gens de guerre, duire et accoustumer a une chose. - Oud. 1616: commander et [faire conduire] gens de guerre, duire et accoustumer a une chose.

5. Oud. 1607: Acogotar, assommer, rompre le col a quelqu'un. Vitt. 16og: ..., [frapper fort sur le chignon du col]. - Oud. 1616: .... [tuer en frappant sur le chignon du col].

6. Oud. 1607: Acaparrado, qui est mis en sauveté sous la faveur d'un autre. - Vitt. 16og: [Caché sous le manteau d'aultruy, et] qui est mis en sauveté sous la faveur d'un autre. - Oud. 1616: [caché soubs le manteau d'autruy] pour y etre a sauveté et soubs sa faveur. 7. Oud. 1607: Acacia, Çumo, une sorte d'espine portant fruict, com mune en Egypte.-Vitt. 16o9: Acacia, [sorte de gomme Arabique qui distile d'] une sorte d'espine portant fruict, commune en Egypte.Oud. 1616: ..., [une sorte de gomme Arabique, qui distile d'] une espine.

8. Oud. 1607: Abejera o Torongil, herbe nommee melisse. - Vitt. 16og: Abejera o Torongil, [Cidrera, citronnelle,] herbe nommee melisse. - Oud. 1616: ... herbe nommee melisse, [citronnelle].

9. Oud. 1607: Acanalado, o Acañalado, fait par canaux, canelé, enjablé. - Vitt. 16og: Acanalado, fait par canaux, canelé, eniablé. - Id.: Acañalado, [fait de cannes et roseaux]. - Oud. 1616: Acanalado, o Acañalado, fait par canaux, canelé, enjablé, [fait de canes].

Nada hay que comentar sobre las variantes marcadas con los números $1,2,3$ y 8 . La cuarta es una muestra del afán de precisión de Oudin; en la quinta se introduce un cambio semántico y de re-

${ }^{5}$ Pongo entre corchetes, también en este caso, la parte que Oudin añadió a sus definiciones de $160_{7}$; se advierte fácilmente que en todos los casos sus adiciones provienen directa o indirectamente de Vittori. 
dacción: nótese que, en la 7 , Oudin prefiere dar dos explicaciones separadamente ${ }^{6}$; en el último ejemplo Vittori distingue los significados de acanalado y acañalado, y por consiguiente registra esas voces en dos artículos distintos, en tanto que Oudin - si bien acepta la adición de su colega-conserva inexplicablemente ambas voces dentro de un mismo artículo. Cabría preguntarse si acañalado es forma atestiguada.

El primero de los grupos antes citados abarca unos 20 artículos; son los casos en que Oudin acepta sin cambio alguno las adiciones de Vittori, las cuales suelen ser de tres tipos: a) inclusión de un nuevo significado o matiz semántico; b) ampliación o glosa; y $c$ ) ampliación, no del texto explicativo, sino de la palabra definida. Los ejemplos que siguen están tomados de Oudin 1616 (va entre corchetes la parte copiada de Vittori):

a) Abatir, abbattre, ietter par terre, [deprimer].

Aburrimiento, desplaisance, desplaisir, fascherie, desespoir, desgoustement, [hayne, horreur].

b) Acrisolado, affiné, apuré, [passé par le creuset et couppelle]. Abarca, une espece de chausseure de paysan, [qui enveloppe les pieds avec du drap, puis les couvre par dessus de cuir crud, lacé avec cordes]: c'est aussi une sorte de brodequin.

c) Abarraganarse, [Amancebarse], ...

Abarraganado, [Amancebado], ...

Al aceptar o rechazar las adiciones de Vittori, Oudin obra caprichosamente y no aprovecha bien las mejoras de su colega. Puede así advertirse en los siguientes casos:

$$
\text { VITTORI } 1609
$$

Abarraganamiento, [Amancebamiento].

Aburrimiento, ... [hayne, horreur]. Aburrir, ... [abhorrer].

Acrisolado, affiné, apuré, [passé par le creuset et couppelle].

Acrisolar, affiner, purifier, [passer ${ }^{\top}$ par le creuset et couppelle].
OudIN 1616

Abarraganamiento, [sin el sinó. nimo recogido por Vittori, pero en Abarraganarse y Abarraganado sí acepta las adiciones de Vitt.].

Como en Vittori

Excluye abhorrer

Como en Vittori

Omite lo que va entre corchetes.

Por último, los artículos del segundo grupo suman también un total de 20 casos. En vista de la inconsecuencia con que actúa Oudin. sería inútil tratar de explicar por qué omite esas 20 adiciones de

- Procedimiento que distingue a Oudin de Vittori, quien por lo general tiende a combinar en una sola dos definiciones distintas.

7 Vittori omite el verbo passer, sin duda por descuido. 
Vittori. En los ejemplos siguientes cito por el texto de este último, encerrando entre corchetes lo que añade al de Oudin de 1607 ; en todos estos casos, la edición de Oudin de 1616 repite puntualmente las definiciones de la primera edición:

1) Acoceamiento, regimbement, [ruade]. - Cf. Oud. 1607 y 1616: Acoceador, regimbeur, rueur des pieds, bailleur de coup de pieds. Abezado, accoustumé, duit à quelque chose, [instruict, endoctriné]. Abezamiento, coustume, accoustumance, [instruction, enseignement]. - Cf. Oud. 1607 y 1616: Abezar, enseigner, monstrer, instruire, accoustumer.

2) Acreditar, mettre en credit, [donner foy et creance].

Aborrascar, s'enfler, et s'eslever la mer, tempester, [faire bourrasque].

Abejeria, lieu où il y a force abeilles, [essain de mouches à miel]. Acometer, assaillir, attaquer, entreprendre, agresser, [s'advancer à faire quelque chose].

3. Abotonar los arboles, Brotar, boutonner comme font les arbres, vignes et autres plantes, bourionner, [germer, pousser boutons].

También en estos casos queda patente la irregularidad con que Oudin admitía las adiciones de Vittori (cf. acoceamiento, abezado y abezamiento). En el apartado segundo, cito las adiciones que Oudin pudo considerar desusadas o erróneas, y en el tercero ofrezco una muestra de adición que pudo parecerle carente de interés.

Todo lo hasta aquí dicho sirve para establecer la relación que guardan entre sí los diccionarios de Oudin y Vittori, relación que podría definirse como de mutuo plagio. Queda aún por determinar la fuente -o las fuentes- en que se basó Vittori aparte del Tesoro de Oudin. A este respecto, sólo puedo aventurar algunas observaciones que acaso ayuden a solucionar la cuestión.

En mi opinión, Vittori sólo se sirvió de una fuente más, y no de varias; me baso en dos razones por lo menos; la primera y principal es de indole cronológica: el Tesoro de Oudin apareció en enero de ${ }_{1607}$, y el de Vittori en 1609 (no sabemos en qué mes); en este intervalo, el lexicógrafo ginebrino tuvo que añadir cerca de 3,00o artículos y hacer casi igual número de adiciones o cambios a las definiciones de Oudin; al mismo tiempo, iba preparando la traducción italiana. Si de esos dos años de intervalo descontamos el tiempo que requeriría la impresión del libro, comprenderemos que, aun contando con la ayuda de varios colaboradores, apenas quedaría a Vittori tiempo suficiente para cotejar el texto de Oudin con algún otro diccionario. Por la misma razón cronológica, debemos rechazar la posibilidad de que Vittori añadiera alguna contribución verdaderamente original, fruto, por ejemplo, de lecturas o investigaciones propias.

En segundo término, ciertas razones estilísticas me afirman en 
mi idea de que la fuente de Vittori fue única; como ya hemos advertido, entre las adiciones hechas por Vittori al texto de Oudin y las que posteriormente aprovechó éste para la segunda edición de su Tesoro, se aprecia notable diferencia en el uso de los artículos definidos e indefinidos y en la construcción partitiva: es Oudin quien, con sorprendente regularidad, añade esas partículas a las explicaciones tomadas de Vittori. Del simple examen de los préstamos que Vittori tomó de Oudin, se deduce que esa particularidad estilística de Vittori no debe ser personal, sino que procede de un desconocido modelo, a quien supongo que plagió tan servilmente como a Oudin.

No sería descabellado afirmar, además, que esa otra fuente puede haber sido algún diccionario español-francés publicado hacia 1606 en Bruselas o en Ginebra. Si esa obra hubiese aparecido antes, o si se hubiera editado en París, Oudin la habría conocido y se habría servido de ella en la edición de 1607 de su Tesoro. Cabría también pensar que Vittori utilizó, no un diccionario español-francés, sino un léxico de español y alguna otra lengua (español-latín o flamenco, por ejemplo); lo seguro es que las adiciones - tanto los artículos nuevos como las múltiples ampliaciones hechas por Vittori a las definiciones de Oudin- no son fruto de su esfuerzo personal, pues sospecho que su competencia y sus conocimientos sobre las lenguas española y francesa dejaban mucho que desear. Aunque cabe dentro de lo posible, no creo, por lo dicho, que Vittori se sirviera de un diccionario intermedio, que sería - pongamos por caso- uno de español-latín y otro de latín-francés.

En todo lo dicho hasta aquí he supuesto -fundándome en la gran semejanza entre el Tesoro de Vittori de 1609 y el de Oudin de 1616- que éste plagió a aquél. Sin embargo, se podría replicar con toda lógica que esa semejanza puede deberse al hecho de que ambos autores utilizaran una misma fuente. Trataré de demostrar que no fue así: observemos, ante todo, que -como ya queda asentadoOudin se mofa de la absurda traducción italiana que Vittori hace de su definición de cedilla. Esto prueba, evidentemente, que conocía la obra de Vittori y que la había examinado con cuidado. Por otro lado, suponiendo que Oudin tuviera a mano el diccionario utilizado por Vittori, no sería lógico pensar que se diera a una tarea ya realizada satisfactoriamente por su colega; mucho más cómodo le resultaría copiar todo o parte de lo ya reunido.

Mi convicción de que Oudin no consultó personalmente el modelo utilizado por Vittori se basa, sobre todo, en el análisis detallado de los materiales añadidos en la segunda edición de su Tesoro. He confrontado las dos primeras ediciones de esta obra y he formado una lista completa de las adiciones que aparecen en el texto de 1616. Al comparar esta lista con el diccionario de Vittori, descubrí 
que en cada página de Oudin 1616 hay un promedio de 4 ó 5 artículos que aparecen también en Vittori. Este cotejo me deparó una sorpresa: en casi 6o páginas (desde la voz puyas hasta socabones) ni una sola de las adiciones apuntadas en mi lista se encuentra en el libro de Vittori; a partir de socabones reaparecen las coincidencias. Pronto descubrí que esas 60 páginas del Tesoro de Vittori son copia fiel del texto de Oudin 1607; no hay en ellas ni una sola adición. No sé a qué atribuir esta laguna; lo importante es que nos permite hacer algunas deducciones. Es preciso advertir, antes de ello, que aproximadamente la mitad de las adiciones incluidas en mi lista se hallan en el vocabulario de Vittori; la otra mitad procede de distintas fuentes. Pues bien, el número de anotaciones de mi lista correspondientes a las páginas que van entre puyas y socabones, disminuye también en un 50\%, disminución atribuible, como es obvio, a la laguna del texto de Vittori.

He aquí los resultados de mis cálculos: las palabras de mi lista incluidas entre puyas y socabones suman un total de 268 ; estas voces corresponden a unas 60 páginas del texto de Oudin. Al calcular cuántas páginas del Tesoro correspondian a cada 268 palabras del resto de esta lista, hallé que la cantidad oscilaba entre un mínimo de 22 páginas y un máximo de 46 (término medio de 33 ). Este medio proporcional es aproximadamente la mitad de 6o, de donde se deduce que Oudin copió a Vittori, y no a una fuente común. De lo contrario, la cantidad de términos adoptados por Oudin de ese modelo común habría sido proporcionalmente uniforme a lo largo de todo su diccionario.

Para terminar, juzgo necesario decir unas palabras sobre las ediciones conocidas del Tesoro de Vittori, posteriores a las de 1609 y $1606^{8}$, o sea, las de 1637 y 1644 . En ellas se añade una tercera parte de italiano-francés-español, cuya portada reza así: “Terza parte / del tesoro delle / tre lingve, italiana, / francese, e spagnuola. / Dove sono le voci italiane / dichiarate in francese e spagnuolo, per aiutar chi desidera / nelle tre sudette lingue perfettamente comporre. / Hora nvovamente posta in / luce, cauata da diuersi autori e lessicografi, / massime del vocabolaro della / Crvsca". Siguen las observaciones al lector (idénticas en ambas ediciones), en que el autor afirma haber revisado cuidadosamente la obra: "Non è merauiglia dunque se'l presente Tesoro gl'anni adietro stampato, fù così diffettoso mentre la prima man sola auea auuto; hor ch'è stato ritoccato, e corretto in guisa, che non v'è pur colonna, non che facciata, dà cui non s'habbin tolti diuersi errori...". Esta afirmación es en gran parte cierta: comparando las definiciones italianas de la Parte I (españolfrancés-italiano) de las ediciones de 1606 y 1637 , advertiremos que

${ }^{8}$ Por evitar confusiones, sigo empleando la falsa fecha de 16 o6 para referirme a la segunda edición. 
en esta última aparecen completamente reelaboradas. En cambio, las definiciones de las ediciones primeras suelen estar equivocadas o ser confusas. Los ejemplos que registro a continuación muestran los diversos tipos y la distinta extensión de esas correcciones ${ }^{9}$ :

\section{VITTORI 1606}

Aba el lobo, cry que l'on fait au loup, gare le loup, (gridare al lupo).

Abadengo, Lo del abad, ce qui appartient a l'Abbé, (quello, che appertiene allo Abate).

Abadejo, Aue, petit oiseau appellé hoche-queuë, ou hochecue, et selon aucuns le roitelet, (coacciole, che sono uccelletti).

Abalançarse, se lancer, se hazarder, se ietter en un danger, se mettre au hazard, (porta, o uscio).

Abarcado, y Abraçado, embrassé, prins, attrappé, accroché, (abbracciatosi insieme).

Abarraganarse, Amancebarse, estre adultere, ou concubinaire, (essere adultero, o puttanero).

Abastar, o Abastançar, suffire, abonder, fournir, garnir, munir, pourvoir, (abastanza, soprabondante).

Abollar, o Abollonar, faire bouillonner, comme quand il pleut, ou quand le pot boult, voyez Bollo, (far bollire, o le piogge fare delle gonfie).

Abonarse, s'ameliorer, (si assicurare di avantaggio).
VITTORI 1637

(al lupo, al lupo)

(cio, che appartiene allo Abate)

(cutreppola)

(gettarsi, lanciarsi)

(abbracciato insieme)

(concubinarsi, far practica con meretrici)

(bastare)

(far bollire, come quando piove, o la pentola bolle)

(migliorarsi, farsi bonaccia)

En menos de cuatro páginas del texto hallo 6o cambios similares. Es evidente que el autor de estas correcciones, contrariamente a lo hecho por el traductor de la primera edición, procedía con cuidado y esmero.

Excepción hecha de estas diferencias, los textos de 1606 y 1637 son idénticos. He cotejado las nueve primeras páginas de la Parte I (artículos de voces españolas con definiciones francesas sólo) con los

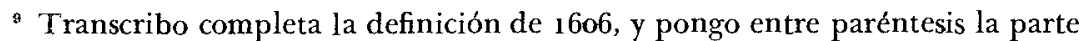
italiana; de las definiciones de 1637 sólo transcribo la glosa italiana, ya que el resto de la explicación se mantiene igual que en la edición de 1606. 
siguientes resultados: con respecto a la palabra que encabeza cada artículo, la edición de 1637 repite todos los errores (14 en total) de la de $\mathbf{1 6 0 6}$, e introduce tres nuevos; en lo que respecta a la glosa francesa, la edición de 1637 incurre en tres nuevos errores, pero corrige otros tantos de la edición anterior. He aquí algunos ejemplos:

VITTORI 1606

Abonase eli tiempo

Abatirse

Abitar,... demeurer

Abondosamente,... epulemment
VITTORI 1697

Como en 1606 [por el].

Abartise

... demorer

. . opulemment

Por consiguiente, las palabras dirigidas al "Amigo Lector" en la Parte I de la edición de 1637 , no pueden tomarse muy al pie de la letra: "Aqui viene el Tesoro... no... suzio y arenisco, antes muy limpio, y purgado, al renes [sic] de aquel que fue emprentado los años andados, que con demasiada priessa luego le echaron a luz, sin reparar, que la materia de los Tesoros hasse de limpiar (como las mugeres) adelante que salgan: ora pues, no es ansi, sino muy corrigido,..." Este tipo de advertencias sólo eran fórmulas convencionales que solían emplearse en cada edición de una obra.

El texto de 1644 es, en casi todos sentidos, idéntico al de 1697 . El tamaño de las páginas es el mismo, y la disposición tipográfica es idéntica, salvo discrepancias mínimas. Aparecen en la edición de 1637, como es casi inevitable, algunas nuevas erratas de imprenta, pero en realidad son admirablemente pocas e insignificantes, habida en cuenta la complicada disposición de un diccionario.

Puede afirmarse que todas las ediciones del Tesoro de Vittori son, en lo que respecta a la parte de voces españolas, esencialmente iguales, con la sola diferencia originada por el número cada vez mayor de errores tipográficos que se descubren en las sucesivas ediciones, de tal modo que las definiciones plagiadas a Oudin $1607 \mathrm{se}$ repiten sin alteración en 1637 . He confrontado las 60 páginas anómalas a que me refería poco antes (páginas que son copia literal de Oudin 1607), y, tomando en cuenta únicamente los epígrafes de cada artículo, he llegado a los siguientes resultados: 1) Vittori repite los errores de Oudin y comete 60 más (promedio de uno por cada página); 2) sólo en un caso corrige Vittori un error de Oudin; 3) Vittori omite -supongo que por inadvertencia- once artículos de Oudin; y 4) los errores de Vittori son relativamente leves, pues por lo común afectan a una sola letra. Ofrezco algunos ejemplos entresacados de los primeros artículos (los errores van subrayados, a no ser que se trate de letras omitidas, en cuyo caso las pongo entre corchetes): 


quajo
quebrantador
queso
quexigueño
quicial
receuir
regueldo
remudadamente

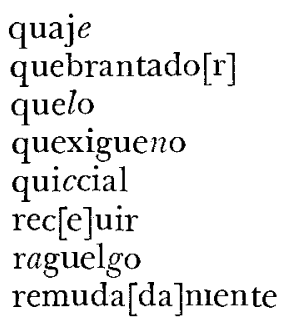

Conclusiones.-Resulta peligroso confiar ciegamente en los editores o en los compiladores de diccionarios publicados en el siglo xvir. En las portadas y en las advertencias de tales obras se declara que se han hecho adiciones, correcciones o revisiones detalladas, lo cual es cosa que puede ponerse en tela de juicio; inclusive los textos deben manejarse con precaución. De los dos lexicógrafos que han sido objeto de nuestro estudio, indudablemente es Oudin el más competente y digno de confianza. El Tesoro de Oudin supera ampliamente al de Vittori, aunque también el de éste puede resultar útil por algunas de las explicaciones y voces que añade al texto de Oudin, y que el gramático francés no incorporó a su diccionario.

LOUIS GOOPER

West Virginia State College. 